\title{
Clinical and Radiologic Outcomes of Minimally Invasive Surgery Transforaminal Lumbar Interbody Fusion with Computer Navigation
}

\author{
Agustin Miguel G. Morales, MD,1,2 Jose Joefrey F. Arbatin Jr., MD, 1,2 \\ Eric Astelo O. Belarmino, MD, ${ }^{1,2}$ Oliver Y. Ong, MD ${ }^{1,2}$ and Hester Renel L. Palma, MD ${ }^{1}$ \\ ${ }^{1}$ Spine Section, Department of Orthopedics, Chong Hua Hospital, Cebu \\ ${ }^{2}$ Spine and Orthopaedics, Cebu
}

\begin{abstract}
Objective. The main objective of this study was to evaluate clinical and radiographic outcomes of computer minimally invasive transforaminal lumbar interbody fusion (CNMIS TLIF).

Methods. Blood loss, operating time, complications, and hospital stay were identified through chart review. Numeric rating scale (NRS) scores for pain were taken during recent follow-ups, and these were compared to the preoperative scores. Three different examiners assessed the pre-operative lumbosacral spine radiographs. At a 2-years follow-up, the patients were evaluated with NRS and the radiographs reassessed by three other examiners.
\end{abstract}

Results. Seventy-four patients with a mean age of 54 years underwent CNMIS TLIF. Average blood loss was 300 $\mathrm{mL}$, operative time was 4.5 hours, and the average length of hospital stay was 8.5 days. A total of four complications were noted in our study. There was an improvement of mean local lordosis and regional lordosis. The paired-sample t-test showed that the anterior, middle, and posterior disc heights at the cage level were significantly increased compared to the pre-operative values.

Conclusion. CNMIS TLIF is a safe and efficient method to achieve spinal fusion. There was a significant improvement in clinical outcomes in terms of pain relief. Radiologic parameters such as local lordosis, regional lordosis, and anterior, middle, and posterior disc heights showed significant improvements at 2-years follow-up.

Key Words: Computer Navigated Minimally Invasive Surgery, Transforaminal Lumbar Interbody Fusion, Computer Navigated Spine Surgery

Presented in the $5^{\text {th }}$ ASEAN MISST and the North American Spine Society (NASS) on June 29, 2019, at the Manila Hotel, Manila, Philippines.

Corresponding author: Hester Renel L. Palma, MD

Department of Orthopedics

Chong Hua Hospital, Cebu

Spine and Orthopaedics, Cebu

Email: hesterrenelpalmamd@gmail.com

\section{BACKGROUND}

Lumbar spinal fusion has been utilized for decades to decrease pain, lessen disability, and improve patients' overall quality of life suffering from degenerative disc disease, spondylolisthesis, and lumbar spinal stenosis. ${ }^{1}$ Due to its popularity among orthopedic surgeons and success rates, spinal fusion has seen a significant change and innovation throughout the years. Several different techniques have been cultivated to improve further this treatment method, one of which has been emphasized by Fujimori et al.; this is the Transforaminal Lumbar Interbody Fusion (TLIF) approach. ${ }^{2}$

TLIF is an adaptation of the more traditional Posterior Lumbar Interbody Fusion (PLIF) and has been an integral part of the management of lumbar fusion since its conception in the 1980s. ${ }^{3}$ This procedure allows the improvement of sagittal alignment. It facilitates circumferential fusion, thus allowing for minimal risk of iatrogenic nerve injury and making it a 
relatively safe approach compared to other open techniques. ${ }^{4}$ Although this and other methods of open spinal surgery have been used to successfully treat patients with degenerative lumbar pathologies, further advancements in spinal fusion surgery allowed for the introduction of minimally invasive lumbar fusion surgery (MIS); this includes MIS TLIF.

The use of minimally invasive surgical techniques is based on the premise that a smaller, less traumatic incision is made in the hope of affording better recovery and outcome. ${ }^{5,6}$ The MIS TLIF technique, in particular, involves the use of a tubular retractor system, which requires minimal neural retraction and provides excellent intradiscal space preparation. ${ }^{7}$ Since introducing the tubular retractor system $\left(\mathrm{METRx}^{\mathrm{TM}}\right.$, Medtronic, Memphis, TN, USA) by Foley and Smith in the late 1990s, an increasing trend in using minimally invasive techniques has been seen regarding the treatment of spinal pathologies. ${ }^{8}$ It has also been noted in studies by Goldstein, 2014; Wong, 2014; and Kahn, 2015 that patients who underwent MIS-TLIF have improved outcome measures, such as reduced blood loss, decreased complication rates, and shorter length of hospital stay..$^{9-11}$

Despite the numerous advantages of MIS, the rates of fusion and operative time are similar between MIS TLIF and open TLIF.-11 It has also been apparent in minimally invasive surgeries that a lack of visualization adds some burden to the surgeon. ${ }^{12,13}$ These findings subsequently prompted the utilization of Computer-navigation in spine surgery (CNSS). This is a form of computer-assisted surgery wherein surgical instruments and bony anatomy are displayed in a monitor providing the surgeon directional assistance. ${ }^{14}$

Several studies have been published to highlight the synergy between computer navigation and minimally invasive technologies with increased computer navigation utilization. One such study is a meta-analysis by Shin in 2012, revealing a significantly lower risk of pedicle perforation for CNSS assisted instrumentation. ${ }^{15}$ However, it also showed no significant difference in total operative time compared to that for non-navigated insertion for all spine regions. ${ }^{14}$
Other literature discuss the improvement of techniques, the performance of screw placement, and vertebral augmentation, but only a few analyzed patient-reported outcome measures following CNSS. ${ }^{12,13}$ Hence, this was the premise of this study, an evaluation of clinical and radiographic outcomes of such patients with a focus on overall recovery. This will allow the surgeon to focus not only on optimizing and integrating this surgical technique into practice but also on weighing the benefits versus the shortcomings of CNSS from a patient's standpoint.

The primary objective of this study was to evaluate clinical and radiographic outcomes of computer minimally invasive transforaminal lumbar interbody fusion (CNMIS TLIF) managed in our institution.

\section{METHODS}

From January 2010 to December 2016, we performed a retrospective review of 143 patients operated with CNMIS TLIF in our institution. We excluded patients with congenital, infectious, neoplastic, and traumatic subluxation and included only those patients with symptomatic degenerative spondylolisthesis, lumbar spinal stenosis degenerative disc disease, and/or disc extrusion. Indications for surgery in patients with lumbar spinal stenosis were a failure of medical management and rehab management. In cases of symptomatic degenerative spondylolisthesis and degenerated disk disease with or without herniated disc, indications were the failure of epidural steroid injection, decreased walking tolerance, and radicular presence of neurologic deficit. We also excluded patients with previous fusion surgery and instrumentation since this may affect patients' clinical outcomes upon follow-up. All patients have at least two years of follow-up. Excluding these patients, we had 74 patients who fulfilled our criteria and were included in our study. The mean age of our patient was 54 , ranging from 40 to 85 years old. Common radiologic MRI findings gathered were lateral stenosis, foraminal stenosis, and facet joint arthrosis, among

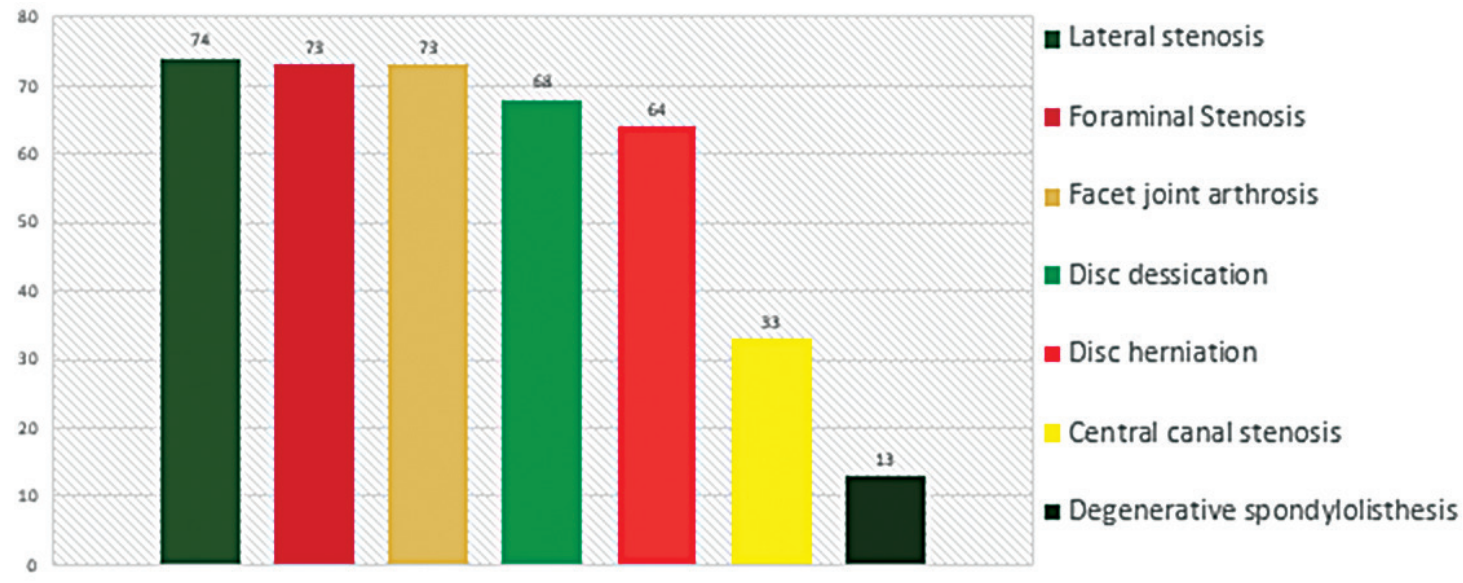

Figure 1. Radiologic MRI findings. 
others (Figure 1). The MRI and radiologic findings were described based on the board-certified radiologist's final report.

After being approved by the institutional review board, informed consent (Appendix A) was given and signed by the participants. Information was first taken through chart review. Blood loss, operating time, and complications were identified. The Numeric Rating Scale, work status, and continuous pain medication were also noted. ${ }^{1}$ Pre-surgical X-ray images were retrieved from the PACS system. Radiologic parameters, especially vertebral disc height (Appendix B), were measured by three people (researcher, certified radiologist, and spine fellow), which were then analyzed. At a 2-years follow-up, we used the numeric rating scale ${ }^{16}$ (Appendix C) to measure the two-year follow-up pain score, and radiographs were reassessed by three different people (researcher, certified radiologist, and spine fellow).

\section{Surgical Technique}

Two fellowship-trained orthopedic spine surgeons performed all surgeries. The computer navigation system consisted of a calibration kit attached to the C-arm, navigation workstation (Kick, BrainLab), an optical camera, and specific instruments (dynamic reference array, pointer, and pedicle probe) with fiducials to be detected by the optical camera. Under general anesthesia, the patient was positioned prone on a radiolucent table, and electrodes were attached for intraoperative neuromonitoring. The reference array was attached to the spinous process two levels above the spine pathology. Next, intraoperative anteroposterior and lateral view radiographs were matched with the patient's pre-operative computer tomography $(\mathrm{CT})$ scan. This CT fluoro-matching enabled the calibration of the fiducials with the patient's CT scan. After calibration, the computer generated a graphic overlay that showed the position of the instruments with respect to the CT scan images. Incision planning was done with the help of the navigation pointer. Two parallel paramedian incisions were made utilizing the interval between the multifidus and longissimus. A tubular retractor system (Met Rx, Medtronic, Sofamor, Danek, Memphis, TN, USA) was introduced over the facet joint.

Pedicles were cannulated using a navigated flat probe. Pedicle screw size and pedicle angulation were determined using computer navigation. Bilateral facetectomy was then performed using a high-speed burr. The ligamentum flavum was identified and freed down to the dura mater. Nerve hooks and nerve retractors were utilized to mobilize the dura medially as a discectomy was performed. Disc space preparation was performed with standard interbody fusion instrumentation. Implant trial placement was performed to determine the optimal size. The polyetheretherketone cage was packed with local bone graft and placed as far anteriorly and midline as possible under fluoroscopic guidance. The operating table was then moved from flexion into the extension to enhance lordosis. Appropriate-length rods were selected and seated into place, and a small amount of additional compression was applied. Hemostasis was obtained. The wound was then copiously irrigated and closed.

\section{Data Analysis}

The data were analyzed using MS Excel and Minitab. Demographic profile, blood loss, hospital stay, complications, pain score, MRI findings. Levels of instrumentation were analyzed using frequency counts, relative frequency, and mean. T-test was used to determine the significant difference of two data sets comparing pre-operative and post-operative followup of local lordosis, regional lordosis, and disc height. The test is considered significant when the $\mathrm{p}$-value is less than 0.05 .

\section{RESULTS}

Average blood loss was $300 \mathrm{~mL}$ (ranges 100-500mL), operative time was 4.5 hours (ranges 3-6 hours), and the average length of hospital stay was 8.5 days. There was a mean improvement in the numeric rating scale from pre-operation with a mean score of 8.18 to a follow-up mean score of $0.81(\mathrm{SD}=1.07, \mathrm{p}<0.05)($ Table 1$)$. Forty-three patients underwent single-level surgery, while thirty-one patients had multilevel surgery (Table 2).

The mean pre-operative local lordosis of $21.1^{\circ}$ was increased to $22.65^{\circ}$ (SD 13.35, $\mathrm{p}<0.05$ ) following spinal fusion (Table 3). There was a mean increase of $5.17^{\circ}$ of regional lordosis (SD 12.44, $\mathrm{p}<0.05$ ) after surgery. This difference has shown to be statistically significant increased (Table 4).

Table 1. Pre-operative and 2-year follow-up numeric rating scale

\begin{tabular}{|c|c|c|c|c|c|c|}
\hline \multirow{2}{*}{ Pain Score } & \multicolumn{2}{|c|}{ Pre-operative } & \multicolumn{2}{|c|}{ 2-year follow-up } & \multirow{2}{*}{$\begin{array}{c}95 \% \mathrm{Cl} \text { for } \\
\text { Mean Difference }\end{array}$} & \multirow{2}{*}{$t$} \\
\hline & $M$ & SD & $M$ & SD & & \\
\hline & 8.18 & 0.86 & 0.81 & 1.07 & $-7.71,-7.04$ & $-43.809^{* *}$ \\
\hline
\end{tabular}

Table 2. Level of pedicle screw instruments

${ }^{* *} p<.01$

\begin{tabular}{cc} 
Single level & $(\mathbf{n}=\mathbf{4 3})$ \\
\hline L3 - L4 & 2 \\
L4 - L5 & 26 \\
L5 - S1 & 15 \\
Multiple levels & $(\mathbf{n}=\mathbf{3 1})$ \\
L2 - S1 & 1 \\
L3 - L5 & 5 \\
L3 - S1 & 8 \\
L4 - S1 & 17 \\
\hline Total & $\mathrm{N}=\mathbf{7 4}$ \\
\hline
\end{tabular}

Table 3. Local Lordosis

\begin{tabular}{|c|c|c|c|c|c|c|}
\hline \multirow{2}{*}{$\begin{array}{l}\text { Local } \\
\text { Lordosis }\end{array}$} & \multicolumn{2}{|c|}{ Pre-operative } & \multicolumn{2}{|c|}{ 2-year follow-up } & \multirow{2}{*}{$\begin{array}{c}95 \% \mathrm{Cl} \text { for } \\
\text { Mean Difference }\end{array}$} & \multirow{2}{*}{$t$} \\
\hline & M & SD & M & SD & & \\
\hline & $21.18^{\circ}$ & 12.00 & $22.65^{\circ}$ & 13.35 & $-5.88,2.94$ & $-1.882^{*}$ \\
\hline
\end{tabular}


Table 4. Regional Lordosis

\begin{tabular}{|c|c|c|c|c|c|c|}
\hline \multirow{2}{*}{ Regional Lordosis } & \multicolumn{2}{|c|}{ Pre-operative } & \multicolumn{2}{|c|}{ 2-year follow-up } & \multirow{2}{*}{$\begin{array}{c}95 \% \mathrm{Cl} \text { for } \\
\text { Mean Difference }\end{array}$} & \multirow{2}{*}{$t$} \\
\hline & $M$ & SD & $M$ & SD & & \\
\hline & $33.70^{\circ}$ & 12.46 & $38.87^{\circ}$ & 12.44 & $-9.91,-0.42$ & $-2.881^{*}$ \\
\hline
\end{tabular}

${ }^{*} p<.05$

Table 5. Disc height at cage level

\begin{tabular}{|c|c|c|c|c|c|c|}
\hline & \multicolumn{2}{|c|}{ Pre-operative } & \multicolumn{2}{|c|}{ 2-year follow-up } & \multirow{2}{*}{$\begin{array}{c}95 \% \mathrm{Cl} \text { for } \\
\text { Mean Difference }\end{array}$} & \multirow{2}{*}{$\mathbf{t}$} \\
\hline & $M$ & SD & M & SD & & \\
\hline Anterior Disc Height (Cage) & $8.61 \mathrm{~mm}$ & 2.90 & $11.52 \mathrm{~mm}$ & 2.76 & $3.56,2.25$ & $8.837^{* *}$ \\
\hline Middle Disc Height (Cage) & $7.72 \mathrm{~mm}$ & 2.72 & $10.76 \mathrm{~mm}$ & 2.50 & $3.76,2.32$ & $8.455^{* *}$ \\
\hline Posterior Disc Height (Cage) & $6.26 \mathrm{~mm}$ & 1.97 & $8.82 \mathrm{~mm}$ & 2.64 & $1.92,3.20$ & $7.933^{* *}$ \\
\hline
\end{tabular}

${ }^{* *} p<.01$

Table 6. Summary of complications

\begin{tabular}{|c|c|c|c|c|c|c|c|}
\hline Patient & Operation & Rate & Complication & Levels & Identified & Intervention & Condition \\
\hline $\mathrm{RC} / 74 \mathrm{M}$ & MIS TLIF L4 S1 & $2 / 115(0.02 \%)$ & Screw malposition & Multi & $\begin{array}{l}\text { Immediate } \\
\text { post-op }\end{array}$ & $\begin{array}{l}\text { Repositioned } \\
1 \text { day post-op }\end{array}$ & $\begin{array}{l}\text { Clinically no signs of } \\
\text { neurologic deficit }\end{array}$ \\
\hline GC / 68F & MIS TLIF L4 S1 & $2 / 115(0.02 \%)$ & Screv & Multi & $\begin{array}{l}\text { Immediate } \\
\text { post-op }\end{array}$ & $\begin{array}{l}\text { Repositioned } \\
1 \text { day post-op }\end{array}$ & $\begin{array}{c}\text { Clinically no signs of } \\
\text { neurologic deficit }\end{array}$ \\
\hline $\mathrm{JB} / 77 \mathrm{M}$ & MIS TLIF L4 L5 & $1 / 115(0.02 \%)$ & $\begin{array}{l}\text { Superficial surgical } \\
\text { site infection }\end{array}$ & Single & $\begin{array}{l}1 \text { week } \\
\text { post-op }\end{array}$ & $\begin{array}{l}\text { Debridement and } \\
\text { closure of wound }\end{array}$ & $\begin{array}{l}\text { Healed wound after } 2 \text { weeks } \\
\text { with no signs of infection }\end{array}$ \\
\hline $\mathrm{JD} / 76 \mathrm{M}$ & MIS TLIF L4 L5 & $1 / 115(0.01 \%)$ & Dural tear & Single & Intra-op & Dural repair & Clinically no signs of dural leak \\
\hline
\end{tabular}

The mean anterior, middle and posterior disc height at the cage level has significantly increased pre-operatively from $8.61 \mathrm{~mm}, 7.72 \mathrm{~mm}, 6.26 \mathrm{~mm}$, respectively, to $11.52 \mathrm{~mm}$, $10.76 \mathrm{~mm}, 8.82 \mathrm{~mm}$, upon 2-year follow-up. This showed a significant increase with a p-value of $<0.01$ (Table 5).

\section{Complications}

There were four complications (Table 6). There were 2 cases of screw malposition at the $\mathrm{S} 1$ level in which revision was done the next day. One patient had a surgical site infection in which debridement was done. There was one dural tear that was treated intraoperatively.

\section{DISCUSSION}

TLIF aims to restore standard disc height, maintain sagittal alignment, and improve fusion rates. The disadvantage of open TLIF is the extensive soft tissue dissection necessary to expose anatomic landmarks for pedicle screw insertion, facetectomy, and discectomy. The advent of tubular retractors facilitated minimally invasive techniques to aim for smaller incisions, less tissue trauma, and faster recovery. However, CNMIS TLIF is a more technically challenging technique as most of the decompression, interbody fusion, and instrumentation require working in a limited operative field. To overcome this obstacle, surgeons rely heavily on intraoperative $\mathrm{C}$-arm images, increasing radiation exposure to the patient and the surgical team. The introduction of computer navigation improved vision by providing a three- dimensional field of view in sagittal, axial, and coronal planes and the lumbar pathology, and the surgical instrumentation and implants. Thus, our study aimed to demonstrate the synergistic effect of a minimally invasive technique and the use of computer navigation in performing a lumbar fusion procedure for improved clinical and radiologic outcomes.

Our study showed an average blood loss of $300 \mathrm{~mL}$ (100-500 mL), which was slightly increased compared to the meta-analysis study of Lei Xie ${ }^{1}, 2016$ (mean blood loss = $224.4 \mathrm{~mL}$ ). Our study's average operating time was 4.5 hours (270 mins), which was almost similar to the study of Parker, 2013 (average operating time $=274$ mins). ${ }^{17}$ Pain relief is a reliable measure of clinical outcome after spinal fusion surgery, and it is the most highlighted advantage of CNMIS TLIF surgery, as shown in our study. The result of our research showed a significant mean improvement in the numeric rating scale from a mean score of 8.18 to 0.81 ( $\mathrm{p}<0.05$ ).

Restoration of sagittal lumbar lordosis has been increasingly recognized as a significant predictor of clinical outcomes for adult spinal deformity. In a study by Yson et al. in 2012, open TLIF with bilateral facetectomy surgeries improved lumbar lordosis at follow-up in single and multilevel spine involvement. ${ }^{18}$ Our research, using CN MISTLIF, achieved the same result as local lumbar lordosis increased by $1.42^{\circ}$, from $21.18^{\circ}$ to $22.65^{\circ}$ and regional lumbar lordosis increased by $5.17^{\circ}$, from $33.70^{\circ}$ to $38.87^{\circ}$.

The overall complication rate was $5.4 \%(4 / 74)$, in which $0.02 \%(2 / 115)$ were screw malposition. The incidence of prevalent complications in our series was within the range 
of reported overall complication rates of MIS TLIF by Lei Xie in 2016. ${ }^{1}$ The same was true for surgical site infection and dural tear rates of $0.01 \%(1 / 115)$ and $0.01 \%(1 / 115)$, respectively, compared with those reported by Lei Xie which was $0.06 \% .^{1}$

\section{Limitation of study}

This was not a randomized controlled trial with a comparator group. Data was gathered retrospectively through chart review and post-operative follow-up. Patients in this series presented with several diagnoses with back pain and radiculopathy.

\section{Recommendation}

The researchers recommend a prospective study to compare MISTLIF with another comparator.

\section{CONCLUSION}

Computer navigated minimally invasive spine technique for transforaminal lumbar interbody fusion reduced pain and improved local lordosis, regional lordosis, and anterior, middle and posterior disc heights in providing treatment for single to multilevel disease of varying etiology at 2-year follow-up.

\section{Statement of Authorship}

All authors participated in the data collection and analysis and approved the final version submitted.

\section{Author Disclosure}

All authors declared no conflicts of interest.

\section{Funding Source}

This paper has no funding support.

\section{REFERENCES}

1. Xie L, Wu W-J, Liang Y. Comparison between Minimally Invasive Transforaminal Lumbar Interbody Fusion and Conventional Open Transforaminal Lumbar Interbody Fusion: An Updated Metaanalysis. Chin Med J. 2016 Aug; 129(16). 1969-86. doi:10.4103/ 0366-6999.187847.

2. Fujimori T, Le H, Schairer WW, Berven SH, Qamirani E, Hu SS. Does Transforaminal Lumbar Interbody Fusion Have Advantages over Posterolateral Lumbar Fusion for Degenerative Spondylolisthesis? Global Spine J. 2015 Apr;5(2):102-9. doi: 10.1055/s-0034-1396432. Epub 2014 Dec 1. PMID: 25844282; PMCID: PMC4369196.

3. Fritzell P, Hägg O, Wessberg P, Nordwall A, Swedish Lumbar Spine Study Group. 2001 Volvo Award Winner in Clinical Studies: Lumbar fusion versus nonsurgical treatment for chronic low back pain: a multicenter randomized controlled trial from the Swedish Lumbar Spine Study Group. Spine (Phila Pa 1976). 2001 Dec 1;26(23): 2521-32; discussion 2532-4. doi: 10.1097/00007632-20011201000002. PMID: 11725230.

4. Djurasovic M, Rouben DP, Glassman SD, Casnellie MT, Carreon LY. Clinical Outcomes of Minimally Invasive Versus Open TLIF: A Propensity-Matched Cohort Study. Am J Orthop (Belle Mead NJ). 2016 Mar-Apr;45(3):E77-82. PMID: 26991587.
5. Rouben D, Casnellie M, Ferguson M. Long-term durability of minimal invasive posterior transforaminal lumbar interbody fusion: a clinical and radiographic follow-up. J Spinal Disord Tech. 2011 Jul;24(5): 288-96. doi: 10.1097/BSD.0b013e3181f9a60a. PMID: 20975594.

6. Holly LT, Schwender JD, Rouben DP, Foley KT. Minimally invasive transforaminal lumbar interbody fusion: indications, technique, and complications. Neurosurg Focus. 2006 Mar 15;20(3):E6. doi: 10.3171/foc.2006.20.3.7. PMID: 16599422.

7. Arikat A, Zairi F, Assaker R. Minimally invasive transforaminal lumbar interbody fusion: Clinical outcome with a two year follow up. Pan Arab J Neurosurg. 2011; 15:5-8.

8. Kazemi N, Crew LK, Tredway TL. The future of spine surgery: New horizons in the treatment of spinal disorders. Surg Neurol Int. 2013 Mar 19;4(Suppl 1):S15-21. doi: 10.4103/2152-7806.109186. PMID: 23653885; PMCID: PMC3642747.

9. Goldstein CL, Macwan K, Sundararajan K, Rampersaud YR. Comparative outcomes of minimally invasive surgery for posterior lumbar fusion: a systematic review. Clin Orthop Relat Res. 2014 Jun;472(6):1727-37. doi: 10.1007/s11999-014-3465-5. PMID: 24464507; PMCID: PMC4016464.

10. Wong AP, Smith ZA, Stadler JA 3rd, Hu XY, Yan JZ, Li XF, et al. Minimally invasive transforaminal lumbar interbody fusion (MITLIF): surgical technique, long-term 4-year prospective outcomes, and complications compared with an open TLIF cohort. Neurosurg Clin N Am. 2014 Apr;25(2):279-304. doi: 10.1016/j.nec.2013.12.007. Epub 2014 Feb 18. PMID: 24703447.

11. Khan NR, Clark AJ, Lee SL, Venable GT, Rossi NB, Foley KT. Surgical Outcomes for Minimally Invasive vs Open Transforaminal Lumbar Interbody Fusion: An Updated Systematic Review and Meta-analysis. Neurosurgery. 2015 Dec;77(6):847-74; discussion 874. doi: 10.1227/ NEU.0000000000000 913. PMID: 26214320.

12. Tian W, Xu YF, Liu B, Liu YJ, He D, Yuan Q, et al. Computer-assisted Minimally Invasive Transforaminal Lumbar Interbody Fusion May Be Better Than Open Surgery for Treating Degenerative Lumbar Disease. Clin Spine Surg. 2017 Jul;30(6):237-242. doi: 10.1097/ BSD.0000000000000165. PMID: 28632545.

13. Xu YF, Le XF, Tian W, Liu B, Li Q, Zhang GL, et al. Computerassisted, minimally invasive transforaminal lumbar interbody fusion: One surgeon's learning curve A STROBE-compliant article. Medicine (Baltimore). 2018 Jul;97(27):e11423. doi: 10.1097/MD. 0000000000011423 . PMID: 29979443; PMCID: PMC6076066.

14. Xiaobang Hu, Lieberman IH, Future Directions in Minimally Invasive Spinal Surgery. Rothman-Simeone and Herkowitz's The Spine, Seventh Edition Chapter 60 2018, 1011-1015

15. Shin BJ, James AR, Njoku IU, Härtl R. Pedicle screw navigation: a systematic review and meta-analysis of perforation risk for computernavigated versus freehand insertion. J Neurosurg Spine. 2012 Aug;17(2):113-22. doi: 10.3171/2012.5.SPINE11399. Epub 2012 Jun 22. PMID: 22724594

16. Ferreira-Valente MA, Pais-Ribeiro JL, Jensen MP. Validity of four pain intensity rating scales. Pain. 2011 Oct;152(10):2399-404. doi:10.1016/j.pain.2011.07.005

17. Parker SL, Mendenhall SK, Shau DN, Zuckerman SL, Godil SS, Cheng JS, et al. Minimally invasive versus open transforaminal lumbar interbody fusion for degenerative spondylolisthesis: comparative effectiveness and cost-utility analysis. World Neurosurg. 2014 JulAug;82(1-2):230-8. doi: 10.1016/j.wneu.2013.01.041. Epub 2013 Jan 12. PMID: 23321379.

18. Yson SC, Santos ER, Sembrano JN, Polly DW Jr. Segmental lumbar sagittal correction after bilateral transforaminal lumbar interbody fusion. J Neurosurg Spine. 2012 Jul;17(1):37-42. doi: 10.3171/2012.4.SPINE111013. Epub 2012 May 11. PMID: 22578236 . 


\section{APPENDICES}

\section{Appendix A. Informed Consent}

Principal Investigator: Arbatin, Jose Joefrey Jr., MD, FPOA

Research Title: Clinical and Radiologic Outcome of Minimally Invasive Surgery Transforaminal Lumbar Interbody Fusion with Computer Navigation

Affiliations: Chong Hua Hospital, Department of Orthopaedics

This Informed Consent Form has two parts:

- Information Sheet (to share information about the study with you)

- Certificate of Consent

\section{Part I - Information Sheet}

\section{Introduction}

I am Dr. Jose Joefrey Arbatin, Jr., an orthopedic spine surgeon in Chong Hua Hospital. I am researching the effects of Clinical and Radiologic Outcome of Minimally Invasive Surgery Transforaminal Lumbar Interbody Fusion with Computer Navigation. In my research, I will be asking you the current pain score of your back. If you agree, I will include you in my study.

\section{Purpose}

To evaluate the clinical and radiologic outcome of minimally invasive surgery transforaminal lumbar interbody fusion with computer navigation. The result of this study might be able to help the orthopedic surgeons project outcomes through evidence base.

\section{Type of research intervention}

This research will ask patients' pain scores using numeric rating scores in at least two years from the operation. Radiologic $\mathrm{X}$-rays will also be taken as part of our data collection.

\section{Selection of participants}

Patients will be brought in by the orthopedic surgeons and will be assessed by the researcher if the participant meets the criteria.

\section{Voluntary participation}

Your decision as to whether or not you will take part in this study is entirely voluntary.

\section{Duration}

You will be made to answer a questionnaire and have a recent X-ray of the lumbosacral spine anterior-posterior and lateral view, which will take about 15 minutes in total. This will be conducted at follow-up in at least two years from the surgery.

\section{Benefit}

There will be no immediate and direct benefit to you. Depending on the outcomes of this study, it will help the spine surgeons when appraising their patients for the procedure for patients to know the expectations based on the results.

\section{Reimbursements}

You will not be provided with any payment to take part in this research

\section{Confidentiality}

The information that we collect from this research project will be kept confidential. There will be no mention of names in the results of this study.

\section{Sharing of research findings}

If given the opportunity to do so, the results of this study will be published so as other people may learn from this research. 


\section{Right to refuse}

You have the right to refuse to take part in this study. Whether or not you will refuse to participate in the study will not affect the treatment you will receive.

\section{Who to contact}

If you have any questions or concerns, please feel free to ask me since I am willing to take the time to explain to you. If you wish to ask questions later, you may contact any of the following:

Dr. Arbatin, Jose Joefrey, Jr. - 09177799495

Department of Orthopaedics - 2547638

Chong Hua Hospital - 2558000

This research proposal has been reviewed and approved by the Institutional Review Board, a committee whose task is to ensure that research participants are protected from harm.

\section{Part II - Certificate of Consent}

I have been asked to consent to participate in this research study which will involve completing a questionnaire.

I have read the preceding information, or it has been read to me. I have had the opportunity to ask questions about it, and any questions that I have asked have been answered to my satisfaction.

I consent voluntarily to participate as a participant in this study.

Print Name of Parent or Guardian

Signature of Parent of Guardian

Date

I have witnessed the accurate reading of the consent form to the potential participant, and the individual has had the opportunity to ask questions. I confirm that the individual has given consent freely.

Print Name of Witness

Signature of Witness

Date

\section{Statement by the Researcher or Person Taking Consent}

I have accurately read out the information sheet to the potential participant, and the best of my ability, making sure that the participant understands that the following will be done:

1. He/She be made to answer questionnaires on follow-up

2. Radiographic Lumbosacral X-ray image shall be taken

I confirm that the participant was allowed to ask questions about the study, and all the questions asked by the participant have been answered correctly and to the best of my ability. I confirm that the individual has not been coerced into giving consent, and the permission has been given freely and voluntarily.

A copy of this informed consent form has been provided to the participant

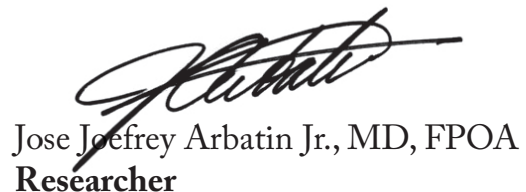

Date 
Appendix B.

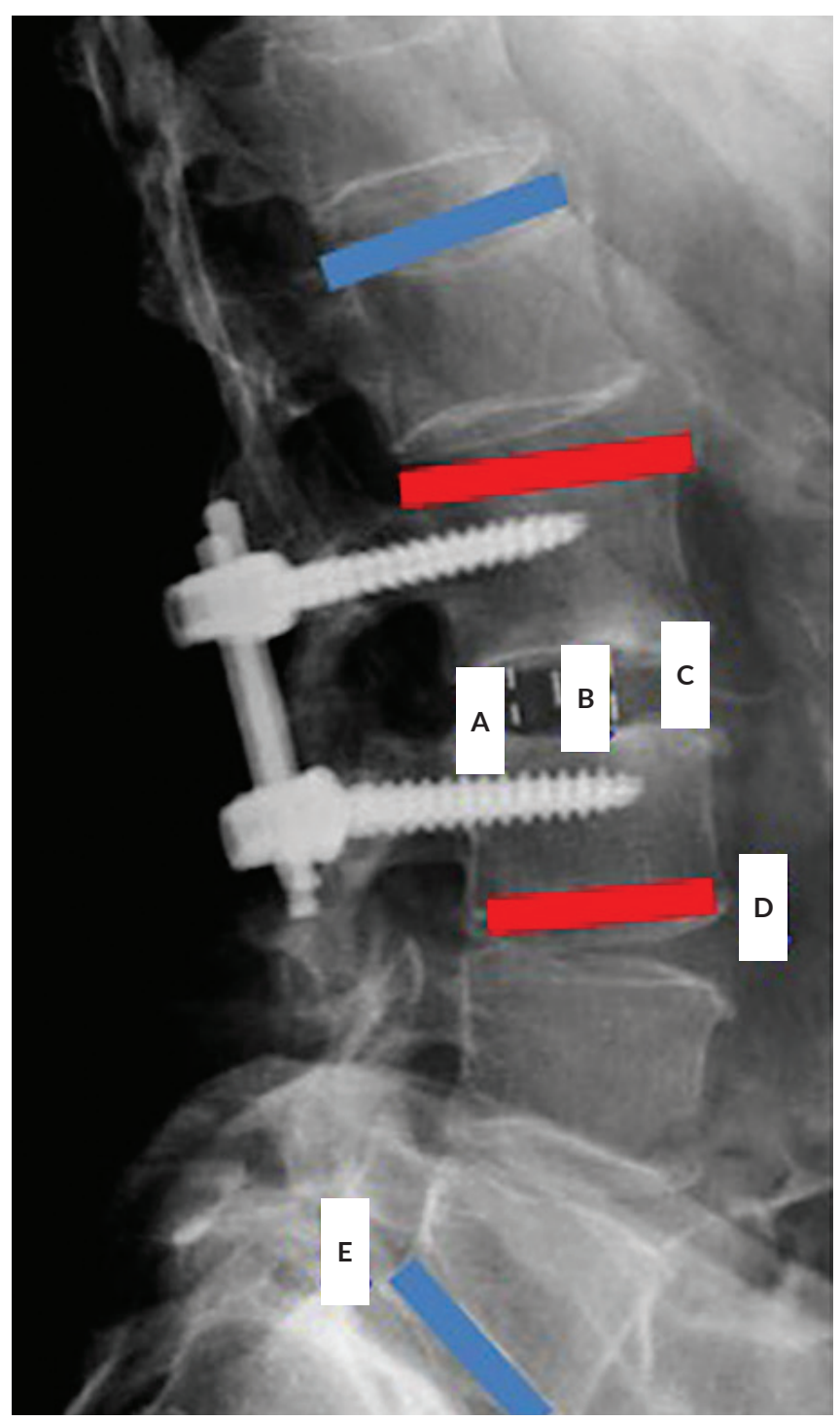

Figure 1. (A) Anterior disc height, (B) Middle disc height, (C) Posterior disc height, (D) Local disc lordosis, (E) Regional lordosis.

\section{Appendix C. Numeric Rating Scale}

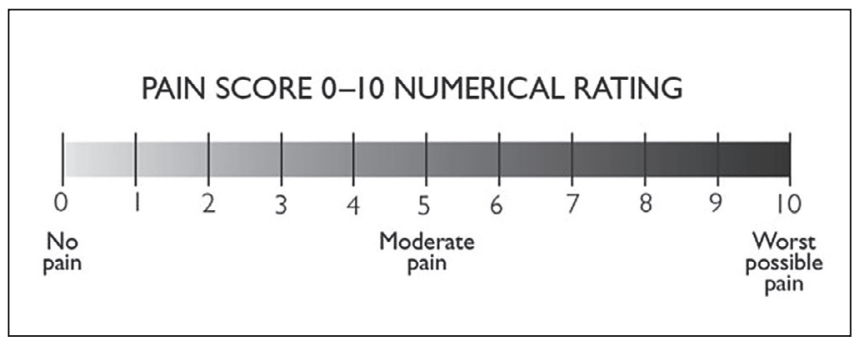

